\title{
Internal Control, Manager ability and Enterprise performance -- Empirical Analysis Based on DEA data Envelopment Model
}

\author{
Duan Huijiao $^{1}$ \\ ${ }^{1}$ Scool of Economics and Management, Beijing Jiaotong University, Beijing, China
}

\begin{abstract}
Internal control has become an important part of corporate governance. This paper selects all Chinese A-share listed companies from 2015 to 2019 as samples to study the relationship between internal control and corporate performance, and to investigate the effect of managers' ability on the process of internal control affecting corporate performance. It is found that there is a significant negative correlation between internal control defects and enterprise performance, which indicates that there are significant internal control defects, which will restrain the enterprise's financial performance; the effectiveness of internal control operation is significantly positively correlated with enterprise performance, which shows that the operation of effective internal control helps to promote the financial performance of enterprises. When we introduce management competence as a moderating variable, we find that competent managers can improve financial performance in an effective internal control environment.
\end{abstract}

\section{Introduction}

The Enron incident broke out in 2001, which aroused the great attention of the United States and even the whole world to the internal control of enterprises. In 2002, the SOX act of the United States was issued, which strengthened the supervision of the audit of listed companies and put forward new requirements for the disclosure of internal control information of listed companies.

Internal control is closely related to the management of the enterprise. The lack of ability of managers and the failure of internal control to play its due role may lead to the decline of the company. Therefore, there are differences in the impact of managers with different levels of ability on the effectiveness of internal control, and there is a close relationship between the quality of internal control and enterprise performance.

The purpose of this study is to find the relationship between internal control and corporate performance through empirical research, and to investigate the effect of managers' ability on the process of internal control affecting corporate performance. We select A-share listed companies from 2015 to 2019 as samples, comprehensively use regression analysis to establish a multiple linear regression model, and try to find the relationship between internal control, management capability and corporate performance through empirical research. The study found that there are significant internal control defects in enterprises, which will restrain the financial performance of enterprises; the operation of effective internal control will help to promote the financial performance of enterprises. When the management ability is introduced as the adjustment variable, it is concluded that the manager is powerless for the company with significant internal control defects; managers' ability will promote the improvement of enterprise performance with effective operation of internal control.

The value of this study is mainly reflected in the following aspects: First, it helps to deepen the understanding of the impact of managers' ability on internal control, and the existing studies have failed to consider the impact of managers' ability on the relationship between internal control and performance. Second, this paper also has a certain practical significance. In practice, we can observe whether managers meet the corresponding conditions, so as to improve management governance, promote the effective implementation of internal control, and ultimately improve enterprise performance and competitiveness.

\section{Data Sources and Methods}

\subsection{Data sources}

This paper chooses all Chinese A-share listed companies from 2015 to 2019 as the object of study. At the same time, the selected samples are screened according to the following rules: (1) excluding the sample data listed and delisted during this period; (2) excluding the sample data of ST, PT, negative assets and the financial industry; and (3) excluding the sample data with missing values and other special circumstances. All the above data are sorted out through CSMAR and Wind database, and the data processing software is Stata15.0. 


\subsection{Variable definition}

According to the research content of this paper, the enterprise performance is selected as the explained variable, the enterprise internal control as the explanatory variable, and the manager ability as the adjustment variable. Combined with the existing research, select the nature of equity, company size, asset-liability ratio, growth ability, free cash flow per share, the number of years on the market, the size of the board of directors, the separation of the two positions, the independence of the board of directors and whether the audit institutions are the big four accounting firms as control variables, and control the year and industry.

\subsubsection{Internal control}

We follow Li Wanfu et al. (2011) ${ }^{[1]}$, chooses the evaluation of internal control inside and outside the enterprise to measure the quality of internal control. The internal control defect (Deficiency) reflects whether there are defects in the enterprise's internal control activities in that year as revealed by the enterprise internal control selfevaluation report. The internal control audit opinion (Audit) represents whether the enterprise employs an external auditor to audit the internal control of the company, and whether the internal control revealed by the internal control audit results is effective.

\subsubsection{Enterprise performance}

The most basic index to consider the financial performance of an enterprise is the profitability index. The commonly used profitability indicators include total return on assets (ROA), return on net assets (ROE) and operating profit margin, in which ROA and ROE can comprehensively reflect the overall performance of enterprises. This paper uses ROA as a variable to measure the financial performance of enterprises.

\subsubsection{Management ability}

Management competence: the quantitative study of management capability generally adopts the data Envelopment Analysis (DEA) method proposed by Demerjian et al. (2012) ${ }^{[2]}$. This method is mainly divided into two steps:

First of all, measure the enterprise production efficiency $(\theta)$, in which the operating income (Sales) is the only output variable, and the net fixed assets (PPE), net R \& D expenditure (NetR\&D), goodwill (Goodwill), intangible assets (Intan), operating cost (CoGS) and sales expenses and management expenses (SG\&A) are input variables, and the model is established (1):

$\max \theta=$

$\frac{\text { Sales }}{\mathrm{V}_{1} P P E+\mathrm{V}_{2} \text { NetR\&D+ } \mathrm{V}_{3} \text { Goodwill }+\mathrm{V}_{4} \text { Intan }+\mathrm{V}_{5} \text { CoGS }+\mathrm{V}_{6} S G \& A}$

Secondly, estimating management capability (MA), enterprise production efficiency can approximately measure management capability. In order to eliminate the influence of enterprise level on production efficiency, this paper selects the following five enterprise level factors that may affect enterprise production efficiency: enterprise scale (Size), market share (Marketshare), free cash flow per share (FCF), listing years (Age), diversification (HHI), to establish the model (2):

$$
\begin{gathered}
\theta=\alpha_{0}+\alpha_{1} \text { Size }+\alpha_{2} \text { Marketshare }+\alpha_{3} F C F+ \\
\alpha_{4} \text { Age }+\alpha_{5} H H I+\varepsilon
\end{gathered}
$$

To establish the $\varepsilon$ in model 2 is to exclude the (MA) of the management ability after the production efficiency at the enterprise level.

\subsection{Model building}

In order to test the influence of internal control on corporate financial performance and explore the regulatory mechanism of managers' ability, this paper constructs the main test model (3):

$$
\begin{gathered}
\text { ROA }_{i, t}=\beta_{0}+\beta_{1} \text { Deficiency }_{i, t}+\beta_{2} \text { Audit }_{i, t}+ \\
\beta_{3} \text { Deficiency }_{i, t} \times M A+\beta_{4} \text { Audit }_{i, t} \times M A+ \\
\sum \text { Controls }_{i, t}+\sum \text { Indu }_{i, t}+\sum \text { Year }_{i, t}+\varepsilon_{i, t}
\end{gathered}
$$

This paper selects the nature of equity, company size, asset-liability ratio, growth ability, free cash flow per share, the number of years on the market, the size of the board of directors, the separation of the two positions, the independence of the board of directors and whether the audit institutions are the big four accounting firms as control variables. and control the year and industry.

The specific descriptions of the above explained variables, explanatory variables and control variables are shown in Table 1.

Table 1 Variable definition

\begin{tabular}{cc}
\hline symbols & Variable definition \\
\hline $\boldsymbol{R O A}$ & EBIT/total asset \\
Deficiency & $\begin{array}{c}\text { If there is a defect in the internal control } \\
\text { of the enterprise, take 1, otherwise take } \\
\end{array}$
\end{tabular}

The external audit carries on the Audit internal control audit and obtains the conclusion that the internal control is effective. Take 1, otherwise take 0 . DEA method Ln(total asset)

Size

Lev

Growth FCF

Total liabilities/total asset

The growth rate of income (net profit + non-cash expensesdividends and capital expenditure)/ total number of shares issued Age Years of listing Directors Ln (number of board members at the end of the term)

Independent The proportion of independent directors to the number of directors

Big4 Whether it is audited by the big four international accounting firms, the big four audit takes 1 , otherwise it takes 0

SOE State holding takes 1, otherwise 0 


\begin{tabular}{cc}
\hline$\sum$ Year & Year dummy variable \\
$\sum$ Industry & Industry dummy variable \\
\hline
\end{tabular}

\section{Summary Statistics}

\subsection{Descriptive statistics}

Table 2 shows the descriptive statistical results of the main variables in this paper. It can be seen that the average (ROA) of corporate performance is 0.0338 , and the standard deviation is less than 0.1 , indicating that as far as the sample companies are concerned, the general profitability of enterprises is not very strong. The (Deficiency) of internal control defects is a virtual variable, the average value is 0.342 and the standard deviation is 0.474 , indicating that there is a big difference among the sample companies in the basic situation of internal control, and the sample companies with weak internal control foundation account for a large proportion. The (Audit) of internal control effectiveness is a virtual variable, with an average of 0.992 and a standard deviation of 0.0875 , indicating that there is little difference in the operation of internal control among the sample companies with a good basis for internal control.

Table 2 Descriptive statistics

\begin{tabular}{cccc}
\hline & $\mathrm{N}$ & Mean & Std \\
\hline ROA & 12,047 & 0.034 & 0.093 \\
Deficiency & 12,361 & 0.342 & 0.474 \\
Audit & 12,048 & 0.992 & 0.088 \\
Big4 & 12,359 & 0.056 & 0.230 \\
Directors & 12,359 & 2.117 & 0.200 \\
Independent & 12,361 & 0.378 & 0.057 \\
Lev & 12,361 & 0.424 & 0.216 \\
Size & 12,361 & 22.340 & 1.310 \\
FCF & 12,361 & -0.103 & 1.499 \\
SOE & 12,361 & 0.351 & 0.477 \\
Age & 12,361 & 13.180 & 7.568 \\
Growth & 12,361 & 0.349 & 4.727 \\
\hline
\end{tabular}

\subsection{The empirical results and analysis}

Table 3 in the regression results of column (1), the coefficient of internal control defect (Deficiency) is- 0.008 and the $t$ value is -4.94 , which is significantly negatively correlated with enterprise performance at the level of $1 \%$, which indicates that there are significant internal control defects, which will inhibit the financial performance of enterprises. In the regression results of column (2), the coefficient of internal control operational effectiveness (Audit) is 0.137 and the $\mathrm{t}$ value is 3.53 , which is significantly positively correlated with enterprise performance at the level of $1 \%$, which indicates that the operation of effective internal control helps to promote the financial performance of enterprises. At the same time, from the regression results, it is found that the corporate size (Size), corporate growth (Growth) and corporate free cash flow (FCF) in the control variables are significantly positively correlated with corporate performance, while the asset-liability ratio (Lev) is significantly negatively correlated with corporate performance, which indicates that enterprises with large scale, good growth, sufficient free cash flow and low financial risk tend to have higher corporate performance.

In order to further verify the mediating effect of the manager's ability, the multiplication term of the internal control defect and the manager's ability (DeMA) and the internal control operation effectiveness and the manager's ability (AuMA) are added in column (3). The results show that in column (3), the coefficient of the multiplicative term (DeMA) of internal control defects and managers' ability is- 0.028 , $t$ value is- 1.02 , but it is not significant, which shows that managers are powerless for companies with major internal control defects, and managers' ability can not play a role in companies with major internal control defects. The coefficient of the multiplicative term (AuMA) of the effectiveness of internal control and the ability of managers is 0.137 and the $t$ value is 9.89 , which is significantly positively correlated with enterprise performance at the level of $1 \%$, which indicates that the ability of managers will positively regulate the influence mechanism of internal control on enterprise performance, that is, the ability of managers plays a part of the regulatory effect in the role of internal control on financial performance. Generally speaking, in enterprises with higher quality of internal control, the system and norms in all aspects are more perfect, and the economic information provided is more accurate and reliable, which can enable managers to give full play to their own ability. help enterprises to carry out production and business activities smoothly, avoid unnecessary problems and mistakes, and improve the financial performance of enterprises.

Table 3 Internal Control, Manager ability and Enterprise performance

\begin{tabular}{cccc}
\hline \multirow{2}{*}{ Variables } & $\boldsymbol{R O A}$ & $\boldsymbol{R O A}$ & $\boldsymbol{R O A}$ \\
& $(1)$ & $(2)$ & $(3)$ \\
\hline Cons & $-0.311^{* * *}$ & $-0.424^{* * *}$ & $-0.316^{* * *}$ \\
& $(-8.14)$ & $(-6.84)$ & $(-4.52)$ \\
Deficiency & $-0.008^{* * *}$ & & -0.002 \\
& $(-4.94)$ & & $(-0.61)$ \\
Audit & & $0.137^{* * *}$ & 0.084 \\
& & $(3.53)$ & $(1.56)$ \\
DeM $\boldsymbol{A}$ & & & -0.028 \\
& & & $(-1.02)$ \\
AuM $\boldsymbol{A}$ & & & $0.137^{* * *}$ \\
& & & $(9.89)$ \\
Size & $0.020^{* * *}$ & $0.019^{* * *}$ & $0.015^{* * *}$ \\
& $(9.32)$ & $(9.86)$ & $(7.93)$ \\
Lev & $-0.225^{* * *}$ & $-0.218^{* * *}$ & $-0.148^{* * *}$ \\
& $(-8.51)$ & $(-9.16)$ & $(-11.68)$ \\
Growth & $0.001^{* * *}$ & $0.001^{* *}$ & $0.001^{*}$ \\
& $(2.13)$ & $(2.09)$ & $(1.74)$ \\
FCF & $0.003^{* * *}$ & $0.003^{* * *}$ & $0.003^{* * *}$ \\
& $(4.91)$ & $(4.96)$ & $(3.52)$ \\
Age & $-0.001^{* * *}$ & $-0.001^{* * *}$ & -0.000 \\
& $(-6.34)$ & $(-6.58)$ & $(-1.30)$ \\
Directors & 0.007 & 0.005 & 0.007 \\
Independent & $(1.47)$ & $(1.19)$ & $(0.74)$ \\
& -0.027 & -0.029 & -0.003 \\
\hline
\end{tabular}




\begin{tabular}{cccc}
\hline & $(-1.49)$ & $(-1.62)$ & $(-0.10)$ \\
Big4 & 0.000 & -0.000 & $0.009^{* *}$ \\
& $(0.04)$ & $(-0.05)$ & $(2.19)$ \\
SOE & $0.005^{* *}$ & 0.002 & 0.000 \\
& $(2.04)$ & $(1.00)$ & $(0.05)$ \\
Year & Yes & Yes & Yes \\
Industry & Yes & Yes & Yes \\
Obs & 12,047 & 12,046 & 2,016 \\
$\boldsymbol{R}^{\mathbf{2}}$ & 0.230 & 0.244 & 0.237 \\
\hline
\end{tabular}

\section{Robustness test}

First of all, in order to increase the robustness of the conclusions and eliminate the interference of other policies or major events on corporate financial performance, this paper removes the data of the previous two years to re-examine the impact of internal control on corporate financial performance. Explore the regulatory mechanism of managers' ability. We find that internal control defect (Deficiency) is significantly negatively correlated with enterprise performance at $1 \%$ level, internal control operation effectiveness is significantly positively correlated with enterprise performance at $1 \%$ level, the multiplication term (DeMA) of internal control defect and manager ability is not significant, and the multiplication term (AuMA) of internal control operation effectiveness and manager ability is significantly positively correlated with enterprise performance at $1 \%$ level, which is consistent with the above conclusion.

Secondly, the relationship between the quality of internal control and financial performance may also be due to the role of reverse impact, that is to say, there may be endogenous problems. For example, the disclosure of internal control defects by management may be due to the pressure of poor operating performance, while profitable companies basically do not have such pressure. Therefore, for companies with positive profits, if they can get the same significant results, this explanation can be excluded to a certain extent. We use the positive and negative of ROA to distinguish profit-making enterprises from lossmaking enterprises, select the companies whose ROA is greater than or equal to 0 as the new sample, and repeat the main test process. We find that in the profitable enterprise sample group, the two internal control quality indicators still have a certain significance, which is consistent with the above conclusion, and the result of this paper is robust.

Finally, replace the explanatory variable. In order to verify the robustness of the above empirical results, this paper draws lessons from the practice of Gan Shengdao and $\mathrm{Hu}$ Mingxia (2014) ${ }^{[3]}$, and uses the "internal control index (IC)" in Dieber risk database as the substitute variable of internal control. The sample companies with IC less than or equal to 33 points are divided into lower internal control groups, and the multiplication term with MA is named ICMA_low. The sample companies with IC greater than or equal to 66 points are divided into higher internal control groups, and the multiplication term with MA is named ICMA_high. Repeating the main test process, we find that the results are consistent with the above conclusions, and the results of this paper are robust.

\section{Conclusion}

Taking Chinese A-share listed companies from 2014 to 2019 as the research object, this paper makes an empirical test on the relationship between internal control and corporate performance. The main results are as follows: (1) there is a significant negative correlation between internal control defects and enterprise performance, which indicates that there are significant internal control defects, which will restrain the enterprise's financial performance; the effectiveness of internal control operation is significantly positively correlated with enterprise performance, which shows that the operation of effective internal control helps to promote the financial performance of enterprises. (2) When the management ability is introduced as the adjustment variable, the multiplication of the internal control defect and the manager ability is not significant, which indicates that the manager is powerless for the company with significant internal control defect; the manager ability will positively regulate the influence mechanism of the internal control on the enterprise performance, that is, the manager ability plays a part of the promotive adjustment effect in the enterprise internal control on the financial performance.

\section{References}

1. Li Wanfu, Lin Bin, Song Lu. The role of Internal Control in Corporate Investment: efficiency Promotion or inhibition? [J]. Management World, 02,81-99+188(2011).

2. Demerjian, P., B. Lev, S. McVay. Quantifying Managerial Ability: A New Measure and Validation Tests. Managerial Science, 07,1229-1248(2012).

3. Gan Shengdao, Hu Mingxia. Management Power, Internal Control and over Investment: based on the evidence of State-owned listed companies [J]. Audit and Economic Research, 05,40-47(2014).

4. Liu Qiliang, Luo Le, Zhang Yaman, Chen Hanwen. Executive centralization, internal control and accounting information quality [J]. Nankai Management Review, 01,15-23(2013).

5. Qiu Xuelin, Liu Hao. Executive performance incentive, manager ability and enterprise performance $[\mathrm{J}]$. Accounting Newsletter, 30,25-28 (2019).

6. Pan Jin, Wang Juncai. Research on Management capability and Capital Investment efficiency: from the Perspective of Investment Cash flow sensitivity $[\mathrm{J}]$. Journal of the Central University of Finance and Economics, 02,90-97(2015). 